\title{
Primeiro ciclo de seleção massal na população PM3 de melão (Cucumis melo L)
}

\section{First mass selection cycle in melon PM3 population (Cucumis melo L)}

\author{
Lucas dos Santos Medeiros ${ }^{1}$, Paulo Vanderlei Ferreira ${ }^{2}$, Islan Diego Espindula de Carvalho ${ }^{3}$, Felipe dos Santos de \\ Oliveira $^{4}$, Jackson da Silva ${ }^{5 *}$
}

\begin{abstract}
Resumo: Objetivou-se com este trabalho realizar o primeiro ciclo de seleção massal na população PM3 de melão. Foi usada a população PM3 de melão, obtida pelo Setor de Melhoramento Genético de Plantas do Centro de Ciências Agrárias da Universidade Federal de Alagoas (SMGP/CECA/UFAL). A colheita foi realizada aos 75 dias após a semeadura. Os frutos foram colhidos totalizaram 1188 frutos, os quais foram analisados a morfologia externa, objetivando a formação de classes fenotípicas em função dos caracteres qualitativos, culminando na obtenção de 40 classes fenotípicas. A classe fenotípica CF 17 foi selecionada por apresentar cor do fruto amarelo, ausência de costelas, ausência de rendilhamento, cor da polpa salmão e formato do fruto arredondado a ovalado. Em seguida foi feita uma seleção dos frutos de melão para os seguintes caracteres quantitativos dentro da classe fenotípica selecionada: peso do fruto acima de 740,0 gramas; diâmetro longitudinal acima de $11,0 \mathrm{~cm}$; diâmetro transversal acima de 10,0 cm, espessura da polpa acima de 1,9 cm; espessura da casca acima de $0,2 \mathrm{~cm}$; diâmetro da cavidade menor que $8,0 \mathrm{~cm}$. A classe fenotípica CF 17 foi à única selecionada.
\end{abstract}

Palavras-chaves: melhoramento vegetal, Cucumis melo L., ciclos de seleção, componentes principais

Abstract: The objective of this work make the first mass selection cycle in melon PM3 population. It was used to melon PM3 population, obtained by the sector of improvement genetic of plants of center science land the Federal University of Alagoas (SMGP/CECA/UFAL). Plants were harvested at 75 days after sowing. The fruits were harvested totaled 1188 fruits, which were analyzed the external morphology, aiming at the formation of phenotypic classes on the basis of qualitative character, culminating in getting 40 phenotypic classes. Phenotypic class CF 17 has been selected for display color of yellow fruit, no ribs, no rendilhamento, color of salmon flesh and rounded to oval fruit shape. Then a selection of melon fruit was made to the following quantitative phenotypic characters within the selected class weight of the fruit above 740.0 grams; longitudinal diameter greater than $11.0 \mathrm{~cm}$; transverse diameter greater than $10.0 \mathrm{~cm}$, flesh thickness above $1.9 \mathrm{~cm}$; shell thickness above $0.2 \mathrm{~cm}$; cavity diameter smaller than $8.0 \mathrm{~cm}$. Phenotypic class CF 17 was the selected one.

Key words: plant improvement, Cucumis melo L., selection cycles, main components

\footnotetext{
*Autor para correspondência

Recebido para publicação em 22/06/2015; aprovado em 28/09/2015

${ }^{1}$ Mestre, Universidade Federal de Alagoas Instituição, Rio Largo-AL; (82) 99913-5055, lucas_medeiros_agro@hotmail.com .

${ }^{2}$ Professor Dr., Universidade Federal de Alagoas, paulovanderleiferreira @bol.com.br.

${ }^{3}$ Doutorando, Universidade Federal de Alagoas, iislandiego@ hotmail.com .

${ }^{4}$ Mestrando em Agronomia (Agricultura), Universidade Estadual Paulista “Júlio de Mesquita Filho”, felipe.smc2011@gmail.com.

${ }^{5}$ Graduando, Universidade Federal de Alagoas, needjackson@ hotmail.com.
} 


\section{INTRODUÇÃO}

O melão, Cucumis melo L., é uma cultura olerícola de grande importância alimentícia. Grande parte de sua produção é destinada ao consumo in natura, como ingrediente de saladas de frutas ou de hortaliças, e também na forma de suco. Segundo Filgueira (2000), o melão apresenta os seguintes valores nutricionais para cada $100 \mathrm{~g}$ de parte comestível: $0,8 \mathrm{~g}$ de proteína; $14 \mathrm{~g}$ de $\mathrm{Ca} ; 0,4 \mathrm{mg}$ de Fe; 16 mg de P; 40 U.I. de Vitamina A; $40 \mu \mathrm{g}$ de Tiamina; $30 \mu \mathrm{g}$ de Riboflavina; 0,6 mg de Niacina; e $23 \mathrm{mg}$ de Vitamina C. Portanto, trata-se de um alimento altamente nutritivo. $\mathrm{O}$ fruto maduro tem propriedades medicinais, sendo considerado calmante, refrescante, alcalinizante, mineralizante, oxidante, diurético, laxante e emoliente (COSTA, 2008).

No Brasil, o agronegócio do melão é um exemplo de evolução rápida de aprimoramento tecnológico e de geração de emprego e renda no semiárido brasileiro. A área plantada passou de 7.877 ha em 1990 para 22.062 ha em 2013 (IBGE, 2013 a) e, nesse período, houve crescimento da produção e da produtividade de $953 \%$ e $339 \%$, respectivamente (IBGE, 2013 b).

A produção brasileira concentra-se no Nordeste (94,97\%), principalmente nos estados do Rio Grande do Norte $(44,97 \%)$, Ceará $(37,54 \%)$, Bahia $(5,90 \%)$ e Pernambuco (3,60\%) (IBGE, 2013 a). Em 2013, foram produzidas 565 mil toneladas, tendo uma área colhida de 22.021 ha, com produtividade de 25,69 $\mathrm{t} \mathrm{ha}^{-1}$ e renda de $\mathrm{R} \$$ 501 milhões de reais. Neste mesmo ano, toda produção de melão em Alagoas ocorreu no município de Mata Grande, com 1,05 mil toneladas, tendo uma área colhida de 30 ha, com produtividade de 35,0 $\mathrm{t} \mathrm{ha}^{-1}$ (a maior do país) e renda de R\$ 864 mil (IBGE, 2013 a).

$\mathrm{O}$ acelerado crescimento da cultura do melão na região Nordeste do Brasil exige a necessidade de um processo contínuo de melhoramento genético dessa espécie vegetal para atender aos anseios dos produtores da região. No entanto, esse processo de melhoramento genético não pode deixar de abordar a qualidade dos produtos agrícolas produzidos (FERREIRA, 2006), o que inclui a possibilidade de associar no melão caracteres nutricionais, maior conservação pós-colheita, aroma e sabor.

A produção nacional de melão é constituída em boa parte do tipo valenciano (Cucumis melo var. inodorus Naudim), cuja tradicional cultivar Valenciano Amarelo é de origem espanhola. Os frutos são globular-alongados, com casca amarelo-canário, com discretas rugas longitudinais, sendo fina, porém resistente. A polpa é espessa, cremeesbranquiçada. O sabor é pobre, com baixo teor de açúcares, porém é aceitável pelo consumidor. Além do aspecto atrativo, os frutos apresentam durabilidade pós-colheita, sendo resistentes ao manuseio rude e ao transporte a longas distâncias. Por outro lado, existe o melão americano (Cucumis melo var. reticulatus Naudin) que apresenta as seguintes características: casca rendilhada, com polpa de coloração salmão, espessa, de fina qualidade, com sabor e aroma mais ricos, sendo menos resistentes ao transporte e ao armazenamento que o melão do tipo valenciano (FILGUEIRA, 2000).

Os programas de melhoramento genético veem oferecendo frequentemente sementes de híbridos e cultivares com fonte de resistência ou atributos qualitativos que atendam às exigências de produtores e consumidores locais. No Brasil, pela insuficiência de trabalhos nesta área os grandes grupos estabelecidos em alguns estados do Nordeste importam sementes híbridas, efetuando testes para avaliar o comportamento nas suas condições de cultivo e que melhor atendam às suas necessidades (PAIVA, 2002).

Apesar da produção de melão no estado de Alagoas ser irrisória, o mercado consumidor se apresenta extremamente promissor. Assim sendo, o estímulo para o cultivo do melão, principalmente entre os pequenos agricultores, poderá tornar o estado de Alagoas, não apenas autossuficiente, mas um grande exportador desta fruta. Desta forma, Alagoas poderá ser equiparado em importância na produção de melão a outros estados do Nordeste brasileiro, já tradicionalmente reconhecidos como grandes produtores como o Rio Grande do Norte e o Ceará.

Desse modo, a execução de um programa de melhoramento genético do melão em Alagoas, que disponibilizará aos agricultores alagoanos cultivares produtivas, adaptadas e que combinem as características de resistência do melão valenciano com as características de qualidade do melão americano, certamente contribuirá para aumentar a produção e a produtividade desta hortaliça no estado de Alagoas, gerando mais empregos e renda, colaborando deste modo com o desenvolvimento socioeconômico da região.

Diante do exposto, o presente trabalho teve como objetivo realizar o primeiro ciclo de seleção massal na população PM3 de melão.

\section{MATERIAL E MÉTODOS}

A pesquisa foi desenvolvida, em condições de campo, na área experimental do Setor de melhoramento genético de plantas do Centro de Ciências Agrárias da Universidade Federal de Alagoas (SMGP-CECA/UFAL), localizado no Campus Delza Gitai, BR 104 Norte, km 85, Rio Largo - AL, nos anos de 2011 e 2012. De acordo com Costa et al. (2011), o solo é classificado como latossolo amarelo coeso argissólico de textura médio-argilosa. O município está situado a uma latitude de $9^{\circ} 27^{\prime} \mathrm{S}$, longitude de $35^{\circ} 27^{\prime} \mathrm{W}$, segundo classificação de Köppen é do tipo As, clima tropical chuvoso com verão seco, a uma altitude média de 100 a 200 m acima do nível do mar, com temperatura e pluviosidade médias anuais entre 24 a $26{ }^{\circ} \mathrm{C}$ e 1300 a $1600 \mathrm{~mm}$, respectivamente (ALVARES et al., 2014).

Foi usada a população PM3 de melão, obtida pelo Setor de Melhoramento Genético de Plantas do Centro de Ciências Agrárias da Universidade Federal de Alagoas (SMGPCECA/UFAL), resultante da hibridação entre as cultivares AMARELO OURO (grupo botânico Inodorus) e HALE'S BEST (grupo botânico Reticulatus), em 1995, seguida de vários ciclos de seleção a partir da geração F2 e posterior agrupamento de progênies de meio-irmãos em função de caracteres de fruto. Esta população apresenta as seguintes características: frutos com formato variando de achatado (CL $<\mathrm{CT})$ até ovalado (CL > CT), com costelas, sem 
rendilhamento, de cor amarela (todas as tonalidades) e tamanho pequeno a médio, podendo segregar para os caracteres mendelianos.

A população PM3 de melão foi submetida a um ciclo de seleção massal, visando à obtenção de uma cultivar que combine as características de resistência do melão valenciano com as características de qualidade do melão americano para o Estado de Alagoas.

Antes do plantio da referida população de melão, foi realizada a análise química do solo no Laboratório de Análises de Produtos Agropecuários do Centro de Ciências Agrárias da Universidade Federal de Alagoas (LAPACECA/UFAL), sendo recomendada a realização da calagem e a adubação. A calagem foi realizada aos 90 dias antes do plantio, utilizando-se 4 t.ha $^{-1}$ de calcário dolomítico. A adubação foi realizada em duas etapas, a primeira ocorreu antes do plantio, utilizando-se $100 \mathrm{~kg} \cdot \mathrm{ha}^{-1}$ de ureia, $100 \mathrm{~kg} \cdot \mathrm{ha}^{-}$ ${ }^{1}$ de superfosfato triplo e $250 \mathrm{~kg} \cdot \mathrm{ha}^{-1}$ de cloreto de potássio. A segunda ocorreu 30 dias após o plantio, sendo aplicados 100 kg.ha ${ }^{-1}$ de ureia.

Inicialmente foi preparado o substrato para a produção das mudas de melão na seguinte proporção: $2: 1: 1$, ou seja, 2 partes de terra; 1 de torta de filtro; 1 de fibra de coco. Foram utilizados 1.600 sacos de polietileno para formação das mudas.

O plantio das sementes da população PM3 de melão foi realizado no dia 15/12/2011 e em cada saco foram colocadas cinco sementes. O desbaste ocorreu aos 15 dias após a semeadura, deixando-se duas plantas por saco.

O transplantio das mudas de melão para o local definitivo ocorreu aos 22 dias após a semeadura, no espaçamento de $2,0 \mathrm{~m} \times 0,25 \mathrm{~m}$, totalizando 1.600 plantas, logo após o desbaste, deixando uma planta por cova.

Foi aplicada uma lâmina de irrigação de $5 \mathrm{~mm} \cdot \mathrm{dia}^{-1}$, por meio do sistema de irrigação por gotejamento, durante todo o ciclo da cultura.

O controle fitossanitário foi executado de forma preventiva, utilizando o inseticida do grupo químico imidacloprido e beta-ciflutrina, Connect ${ }^{\circledR}$, por meio de um pulverizador costal com capacidade de 20 litros, em 2 aplicações, sendo realizada a primeira com os primeiros sinais de aparecimento da praga, e a segunda duas semanas depois, com a dosagem de $40 \mathrm{~mL}$ do produto por aplicação. Também foi aplicado um fungicida sistêmico, do grupo benzimidazol, Cercobin ${ }^{\circledR}$, também com pulverizador costal, sendo realizadas 3 aplicações com o intervalo de uma semana entre as mesmas, depois do início da frutificação, com a dosagem de 5,6 g do produto por aplicação.

A colheita foi realizada aos 75 dias após a semeadura. Os frutos colhidos totalizaram 1.188 frutos, os quais foram transportados para o Laboratório do SMGP-CECA-UFAL, para análise da morfologia externa, objetivando a formação de classes fenotípicas em função dos caracteres qualitativos, os quais foram agrupados nas classes fenotípicas descritas (Tabela 1).

Tabela 1. Características das classes fenotípicas dos frutos da população PM3 de melão.

\begin{tabular}{|c|c|c|c|c|c|}
\hline \multirow{2}{*}{$\begin{array}{c}\text { Classes } \\
\text { Fenotípicas }\end{array}$} & \multicolumn{5}{|c|}{ Características } \\
\hline & Cor do fruto & Costelas & Rendilhamento & Cor da polpa & Formato \\
\hline CF 1 & Amarela & Com & Com & Salmão & Alongado \\
\hline $\mathrm{CF} 2$ & Amarela & Com & Com & Salmão & Arredondado \\
\hline CF 3 & Amarela & Com & Com & Salmão & Achatado \\
\hline $\mathrm{CF} 4$ & Branca & Sem & Sem & Branca & Alongado \\
\hline CF 5 & Amarela & Sem & Sem & Salmão & Alongado \\
\hline CF 6 & Branca & Com & Sem & Salmão & Alongado \\
\hline CF 7 & Verde & Com & Sem & Branca & Arredondado \\
\hline CF 8 & Amarela & Com & Sem & Salmão & Alongado \\
\hline CF 9 & Amarela & Sem & Com & Salmão & Arredondado \\
\hline CF 10 & Amarela & Com & Sem & Branca & Arredondado \\
\hline CF 11 & Branca & Com & Com & Salmão & Arredondado \\
\hline CF 12 & Amarela & Com & Com & Branca & Arredondado \\
\hline CF 13 & Branca & Sem & Com & Salmão & Arredondado \\
\hline CF 14 & Branca & Com & Sem & Branca & Achatado \\
\hline CF 15 & Branca & Sem & Sem & Salmão & Achatado \\
\hline CF 16 & Branca & Sem & Sem & Salmão & Arredondado \\
\hline CF 17 & Amarela & Sem & Sem & Salmão & Arredondado a Ovalado \\
\hline CF 18 & Amarela & Sem & Sem & Salmão & Achatado \\
\hline CF 19 & Amarela & Com & Sem & Salmão & Arredondado \\
\hline CF 20 & Amarela & Sem & Com & Salmão & Alongado \\
\hline CF 21 & Branca & Com & Sem & Branca & Alongado \\
\hline CF 22 & Branca & Sem & Sem & Branca & Achatado \\
\hline CF 23 & Amarela & Com & Sem & Branca & Alongado \\
\hline CF 24 & Verde & Com & Sem & Salmão & Alongado \\
\hline CF 25 & Branca & Com & Com & Branca & Alongado \\
\hline CF 26 & Verde & Sem & Sem & Salmão & Arredondado \\
\hline CF 27 & Branca & Com & Com & Branca & Arredondado \\
\hline CF 28 & Verde & Sem & Sem & Branca & Arredondado \\
\hline CF 29 & Branca & Com & Com & Salmão & Alongado \\
\hline CF 30 & Verde & Sem & Sem & Branca & Alongado \\
\hline
\end{tabular}




\begin{tabular}{|c|c|c|c|c|c|}
\hline \multicolumn{6}{|c|}{ Continuação Tabela 1} \\
\hline \multirow{2}{*}{$\begin{array}{c}\text { Classes } \\
\text { Fenotípicas }\end{array}$} & \multicolumn{5}{|c|}{ Características } \\
\hline & Cor do fruto & Costelas & Rendilhamento & Cor da polpa & Formato \\
\hline CF 31 & Amarela & Sem & Com & Branca & Alongado \\
\hline CF 32 & Verde & Sem & Sem & Salmão & Alongado \\
\hline CF 33 & Verde & Com & Com & Salmão & Alongado \\
\hline CF 34 & Verde & Com & Sem & Branca & Alongado \\
\hline CF 35 & Verde & Sem & Sem & Branca & Achatado \\
\hline CF 36 & Verde & Com & Sem & Salmão & Arredondado \\
\hline CF 37 & Amarela & Com & Com & Branca & Alongado \\
\hline CF 38 & Amarela & Com & Sem & Salmão & Achatado \\
\hline CF 39 & Amarela & Sem & Sem & Branca & Alongado \\
\hline CF 40 & Amarela & Sem & Sem & Branca & Arredondado \\
\hline
\end{tabular}

Em seguida foi feita uma seleção dos frutos de melão para os seguintes caracteres quantitativos dentro da classe fenotípica selecionada: peso do fruto (PF) acima de 740,0 gramas; diâmetro longitudinal (DL) acima de $11,0 \mathrm{~cm}$; diâmetro transversal (DT) acima de $10,0 \mathrm{~cm}$, espessura da polpa (EP) acima de $1,9 \mathrm{~cm}$; espessura da casca (EC) acima de $0,2 \mathrm{~cm}$; diâmetro da cavidade (DC) menor que $8,0 \mathrm{~cm}$.

Os dados dos caracteres quantitativos dos frutos de melão selecionados foram analisados por meio da estatística descritiva, estimando-se a média, a amplitude total, o coeficiente de variação e o intervalo de confiança (95\%), seguindo as recomendações de Ferreira (2000).

Posteriormente foi aplicado o método dos componentes principais para os caracteres quantitativos dos frutos de melão, visando reduzir o número destes nos próximos ciclos de seleção, seguindo as recomendações de Cruz e Regazzi (1997).
A estatística descritiva e método dos componentes principais, foram realizadas por meio do programa estatístico ASSISTAT (SILVA et al., 2002).

\section{RESULTADOS E DISCUSSÃO}

Na Figura 1 estão expostos os resultados das classes fenotípicas de frutos de melão da população PM3, em que a classe 17 (casca amarela, sem rendilhamento, sem costelas, polpa salmão e formato arredondado a ovalado) é a classe de interesse para o programa de melhoramento, sendo então a classe fenotípica selecionada, que obteve um percentual de $13,6 \%$ dos frutos colhidos, totalizando 176 frutos. O grupo formado, resultante da seleção considerando-se as variáveis quantitativas, foi de 54 frutos, representando assim a amostra selecionada para continuidade nos próximos ciclos de seleção, o que significa $4,54 \%$ dos frutos da população em estudo.

Figura 1. Distribuição de frutos de melão da população PM3 nas respectivas classes fenotípicas. Rio Largo-AL, 2013.

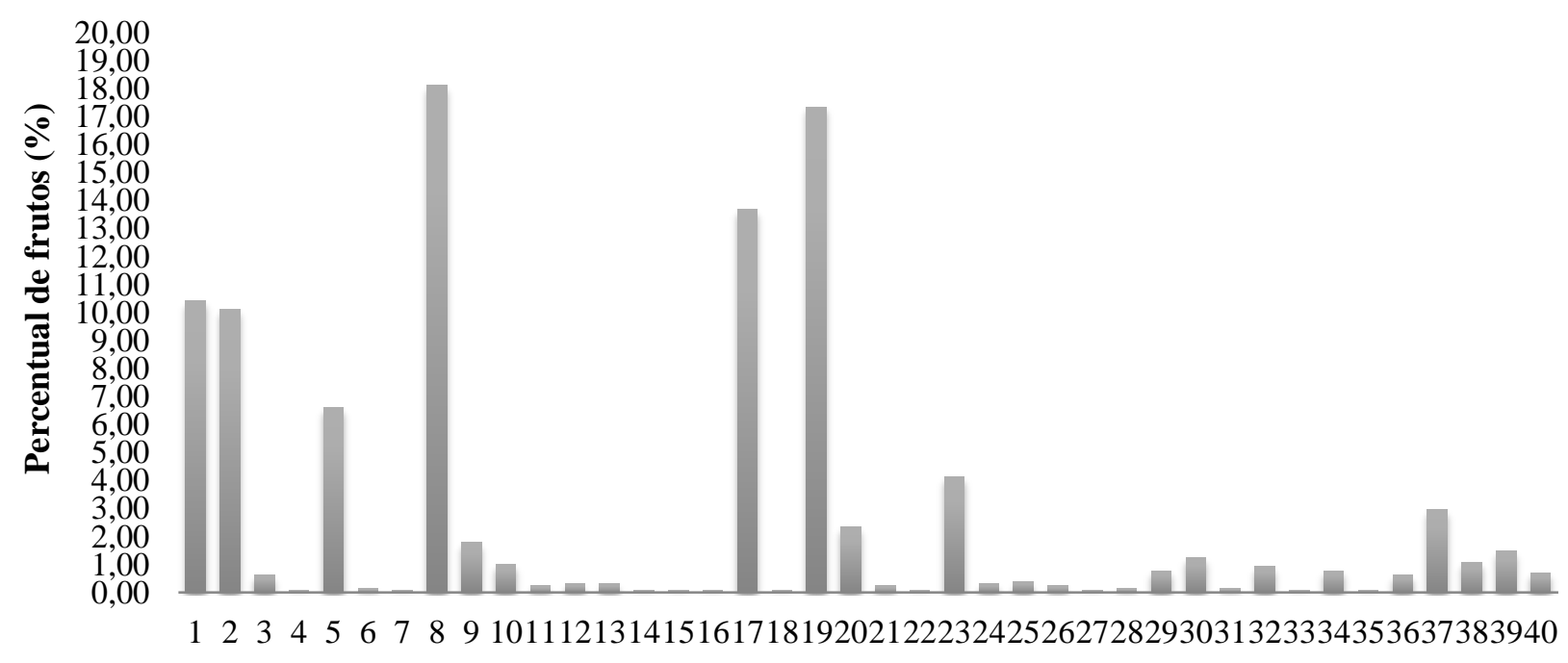

\section{Classes fenotípicas}

Na Tabela 2 consta a comparação entre a média da variável Peso dos frutos, em gramas, da população em estudo (PM3), com a média da amostra selecionada e o acréscimo percentual no peso do fruto da amostra selecionada em relação à população original. Verifica-se um acréscimo de $10,92 \%$ no peso dos frutos da amostra selecionada em relação à população original, muito acima dos resultados encontrados por Silva et al. (2011b), indicando que essa característica terá, possivelmente, um razoável ganho genético, que revelará a superioridade adquirida com esse primeiro ciclo de seleção massal para o caráter em estudo. 
Tabela 2. Comparação da média dos pesos dos frutos (g) da população original (PM3) de melão com a amostra selecionada. Rio Largo-AL, 2013.

\begin{tabular}{ccc}
\hline Populações & Média $(\mathrm{g})$ & Acréscimo $(\%)$ \\
\hline PM3 (Original) & 918,846 & - \\
Amostra selecionada & $1.019,222$ & 10,92 \\
\hline
\end{tabular}

Na Tabela 3 constam os dados descritivos dos 54 frutos selecionados de melão, para as seis variáveis. A variável PF apresentou média de $1.019,22 \mathrm{~g}$, cujo valor foram semelhantes aos obtidos por Castoldi et al. (2008), Charlo et al. (2009a), Queiroga et al. (2008) e Mascarenhas et al. (2010),bem superior aos encontrados por Vargas et al. (2008a). No entanto, inferior aos resultados encontrados por Nunes et al. (2008), Charlo et al. (2009b), Nunes et al. (2011). $\mathrm{O}$ valor de PF obtido neste trabalho, segundo Vargas et al. (2008a), está dentro da faixa comercial, pois existe hoje uma tendência no mercado consumidor de preferir frutos com peso próximo a $1 \mathrm{~kg}$.

Este caráter (PF) apresentou uma amplitude de variação de $892 \mathrm{~g}$, a qual é considerada alta, e uma boa precisão da média, expressa pelo Intervalo de Confiança $(1019,22 \pm$ 61,52). O coeficiente de variação foi relativamente alto $(21,99 \%)$, em função da grande variação dos frutos.

Tabela 3. Análise descritiva dos frutos selecionados de melão na população PM3. Rio Largo-AL, 2013.

\begin{tabular}{|c|c|c|c|c|c|c|}
\hline & $\mathrm{PF}^{(1)}$ & $\mathrm{DT}^{(2)}$ & $\mathrm{DL}^{(3)}$ & $\mathrm{EC}^{(4)}$ & $\mathrm{EP}^{(5)}$ & $\mathrm{DC}^{(6)}$ \\
\hline Média & 1019,22 & 12,01 & 14,84 & 0,38 & 2,69 & 5,82 \\
\hline Amplitude total & 892 & 3,1 & 9,6 & 0,5 & 0,26 & 6,2 \\
\hline $\mathrm{CV}(\%)$ & 21,99 & 6,69 & 15,76 & 29,49 & 19,22 & 15,87 \\
\hline IC $(95 \%)$ & $1019,22 \pm 61,52$ & $12,01 \pm 0,22$ & $14,84 \pm 0,64$ & $0,38 \pm 0,03$ & $2,60 \pm 0,14$ & $5,82 \pm 0,25$ \\
\hline
\end{tabular}

A variável Diâmetro Transversal teve uma média de $12,01 \mathrm{~cm}$, que foi superior aos resultados observados por Silva et al. (2011a) e, inferior à média obtida por Nunes et al. (2011) e Camili et al. (2011) na avaliação de híbridos comerciais de melão.

O Diâmetro Longitudinal apresentou uma média de $14,88 \mathrm{~cm}$, que foi maior que as médias encontradas por Rocha et al. (2010) e Queiroga et al. (2010), e menor que as média obtidas por Bezerra et al. (2009) e Amariz et al. (2009). O caráter Diâmetro Longitudinal e o caráter Diâmetro Transversal, determinarão o índice de formato dos frutos, que é obtido pela razão destes. Percebeu-se que na PM3, os frutos variaram desde arredondado a ovalado, apresentando diferentes índices de formato, o que pode ser objeto de seleção no próximo ciclo de seleção, objetivando homogeneizar a população para esse caráter. Este atributo está relacionado ao acondicionamento e transporte dos frutos, sendo um parâmetro usado para a classificação e adequação dos frutos ao tipo de embalagem e mercado consumidor a que se destina. Para o caráter Espessura da Casca, observa-se que houve uma variação de $0,50 \mathrm{~cm}$ em torno da média $(0,38 \mathrm{~cm})$.

Com relação à variável Espessura da Polpa, a média encontrada foi de 2,69, sendo inferior aos resultados observados por Vargar et al. (2008a), Gondim et al (2009) e Dias et al. (2010).

O caráter Diâmetro da Cavidade teve uma média de 5,82 $\mathrm{cm}$, sendo superior à média encontrado por Charlo et al. (2009a), e menor que a média obtida por Vargas et al. (2008b), o que é vantajoso, pois frutos com menor diâmetro da cavidade sofrem menos injúrias no manuseio, em função da boa aderência das sementes à placenta, o que influencia no tempo de conservação dos frutos. $\mathrm{O}$ fruto ideal deve ter polpa espessa e, consequentemente, uma cavidade interna pequena, pois frutos deste tipo resistem melhor ao transporte e têm maior durabilidade pós-colheita.
As estimativas dos autovalores $(\lambda \mathrm{j})$ correspondentes aos primeiros componentes principais e os coeficientes de ponderação (autovetores) estão apresentados na Tabela 4. De acordo com os dados avaliados referentes às seis variáveis (PF, DT, DL, EC, EP, DC), os três primeiros componentes principais apresentaram estimativas de autovalores superiores a 1,0 (2,0659, 1,5546 e 1,1812, respectivamente), estando de acordo com o que Lopez e Hidalgo (1994) estabeleceram como critério para a seleção dos componentes principais, os quais explicam $80,02 \%$ da variação total encontrada nos dados originais, sendo $34,43 \%$ para o primeiro, $25,91 \%$ para o segundo e $19,68 \%$ para o terceiro.

Também foi determinada a importância relativa das características usadas na seleção de frutos da população PM3 de melão que foi quantificada pelos coeficientes de ponderação (autovetores) das características dos componentes principais (Tabela 4).

O critério adotado foi o descarte das características que menos contribuirão para a seleção de frutos da população PM3 de melão por meio dos maiores elementos dos autovetores associados às características, partindo-se dos últimos componentes principais, considerando o valor absoluto.

Assim sendo, as características de menor importância, no presente estudo, foram hierarquicamente: diâmetro longitudinal (DL), com o maior valor absoluto entre as características $(0,7710)$, para o autovetor seis; espessura da polpa (EP), com o maior valor absoluto entre as características $(0,6041)$, para o autovetor cinco; e diâmetro da cavidade (DC), com o maior valor absoluto entre as características $(0,5681)$, para o autovetor quatro. Estas três características, de um total de seis, podem ser dispensáveis. Portanto, nos próximos ciclos de seleção na população PM3 de melão deverão ser usadas as seguintes características: peso 
do fruto (PF), diâmetro transversal (DT) e espessura da casca (EC).

Este fato evidencia a importância da utilização de técnicas multivariadas (componentes principais) na identificação de caracteres, que realmente devem ser avaliados com base em um estudo prévio da sua contribuição para a variabilidade (PEREIRA, 1989). O interesse nessa avaliação reside na possibilidade de se descartarem caracteres que contribuam pouco para a discriminação da população avaliada, reduzindo, dessa forma, mão-de-obra, tempo e custos despendidos, na experimentação agrícola (Cruz e Regazzi, 1997).

Tabela 4. Estimativas dos autovalores $(\lambda \mathrm{j})$ correspondentes às percentagens de variação explicadas pelos componentes principais e respectivos autovetores (coeficiente de ponderação) das seis variáveis ${ }^{1}$ avaliadas em melão. Rio Largo-AL, 2013.

\begin{tabular}{|c|c|c|c|c|c|c|c|c|}
\hline \multirow{2}{*}{$\begin{array}{l}\text { Component } \\
\text { es principais }\end{array}$} & \multicolumn{2}{|c|}{ Autovalores } & \multicolumn{6}{|c|}{ Autovetores } \\
\hline & $\Lambda \mathrm{j}$ & $\lambda \mathrm{j}(\%)$ & $\mathrm{PF}$ & DT & DL & $\mathrm{EC}$ & EP & $\mathrm{DC}$ \\
\hline Y1 & 2,0659 & 34,43 & 0,6710 & 0,0402 & $-0,0208$ & 0,1346 & $-0,0074$ & $-0,7278$ \\
\hline Y2 & 1,5546 & 60,34 & 0,1464 & 0,5596 & 0,1796 & $-0,7284$ & $-0,3189$ & 0,0290 \\
\hline Y3 & 1,1812 & 80,02 & 0,1671 & $-0,3849$ & $-0,5955$ & $-0,5717$ & 0,3753 & 0,0408 \\
\hline Y4 & 0,7440 & 92,42 & 0,5429 & 0,4023 & $-0,0666$ & 0,2536 & 0,3904 & 0,5681 \\
\hline Y5 & 0,3535 & 98,31 & 0,4440 & $-0,5235$ & 0,1176 & $-0,0072$ & $-0,6041$ & 0,3809 \\
\hline Y6 & 0,1009 & 100,00 & 0,0924 & $-0,3114$ & 0,7710 & $-0,2452$ & 0,4899 & $-0,0032$ \\
\hline
\end{tabular}

PF: peso do fruto; EC: espessura da casca; EP: espessura da polpa; DL: diâmetro longitudinal; DT: diâmetro transversal; DC: diâmetro da cavidade

\section{CONCLUSÕES}

O presente trabalho permitiu as seguintes conclusões:

A classe fenotípica CF 17 foi selecionada por apresentar as seguintes características: frutos de casca amarela, sem rendilhamento, sem costelas, polpa salmão e formato arredondado a ovalado.

Houve um acréscimo de 10,92\% no peso dos frutos de melão na amostra selecionada em relação à população original (PM3).

Os componentes principais PF, DT e DL explicam $80,02 \%$ da variação total encontrada nos dados originais.

\section{REFERÊNCIAS BIBLIOGRÁFICAS}

ALVARES, C. A.; STAPE J. L.; SENTELHAS, P. C.; GONÇALVES, J. L. de M.; SPAROVEK, G. Köppen's climate classification map for Brazil. Meteorologische Zeitschrift, v. 22, n. 6, p. 711-728, 2014.

AMARIZ, A.; LIMA M. A. C.; BRAGA, M. B.; TRINDADE, D. C. G. da; RIBEIRO, T. P.; SANTOS, A. C. N. dos. Conservação pós-colheita de melão cultivado com diferentes tipos de cobertura do solo e com uso de manta agrotêxtil. Horticultura Brasileira, v. 27, n. 2, p. 548-554. 2009.

BEZERRA, F. M. L.; NUNES, M. C. H.; FREITAS, C. A. S. de; SILVA, F. L. da. Desempenho de três híbridos de meloeiro sob dois espaçamentos em ambiente protegido na chapada do Apodi. Revista Ciência Agronômica, Fortaleza, v. 40, n. 3, p. 412-416, 2009.

CAMILI, E. C.; MÜLlER, D. H.; PARMEJIANI, R. S.; MATOS, V. A. T.; BORGES, G., KOBORI, R. Desempenho de híbridos de melão amarelo na Baixada Cuiabana. Horticultura Brasileira, v.29, n. 2, p. 18231831, 2011.
CASTOLDI, R.; CHARLO, H. C. O.; VARGAS, P. F.; BRAZ, L. T. Qualidade de frutos de cinco híbridos de melão rendilhado em função do número de frutos por planta. Revista Brasileira de Fruticultura, Jaboticabal, v. 30, n. 2, p. 455-458, 2008.

CHARLO, H. C. O.; CASTOLDI, R.; VARGAS, P. F.; BRAZ, L. T. Desempenho de híbridos de melãorendilhado cultivados em substrato. Científica, Jaboticabal, v.37, n.1, p.16-21, 2009 b.

CHARLO, H. C. O.; CASTOLDI, R.; VARGAS, P. F.; BRAZ, L. T. Cultivo de melão rendilhado com dois e três frutos por planta. Horticultura Brasileira, v. 27, n. 2, p. 251-255, 2009a.

COSTA C. T. S.; FERREIRA V. M.; ENDRES L.; FERREIRA, D. T. R. G.; GONÇALVES, E. R. Crescimento e produtividade de quatro variedades de cana-de-açúcar no quarto ciclo de cultivo. Revista Caatinga, v. 24, n. 3, p. 56-63, 2011.

COSTA, N. D. A cultura do melão. 2. ed. rev. ampl. Brasília: Embrapa Informação Tecnológica, 2008.

CRUZ, C. D.; REGAZZI， A. J. Modelos biométricos aplicados ao melhoramento genético. Viçosa, MG: Imprensa Universitária, 1997.

DIAS, N. S.; LIRA, R. B.; BRITO, R. F.; NETO, O. N. de S.; NETO, M. F.; OLIVEIRA, A. M. de. Produção de melão rendilhado em sistema hidropônico com rejeito da dessalinização de água em solução nutritiva. Revista Brasileira de Engenharia Agrícola e Ambiental, Campina Grande, v.14, n.7, p.755-761, 2010.

FERREIRA, P. V. Estatística experimental aplicada à agronomia. 3. ed. Maceió: EDUFAL, 2000. 422p. 
FERREIRA, P. V. Melhoramento de plantas: princípios e perspectivas. Maceió: EDUFAL, 2006.

FILGUEIRA, F. A. R. Novo manual de olericultura: agrotecnologia moderna na produção e comercialização de hortaliças. Viçosa: Editora da UFV, 2000. 402 p.

GONDIM, A. R. O.; NEGREIROS, M. Z.; MEDEIROS, J. F.; PORTO, D. R. Q.; NETO, A. J. A.; MENEZES, J. B. Qualidade de melão 'Torreon' cultivado com diferentes coberturas de solo e lâminas de irrigação. Revista Ceres, v. 56, n. 3, p. 326-331, 2009.

INSTITUTO BRASILEIRO DE GEOGRAFIA E ESTATÍSTICA (IBGE). Versão Eletrônica. Disponível em <http://http://www.ibge.gov.br/estadosat>, 2013a. Acesso em: 01 de maio de 2015.

INSTITUTO BRASILEIRO DE GEOGRAFIA E ESTATÍSTICA (IBGE). Banco de dados agregados. Disponível em: <http://www.sidra.ibge.gov.br/bda/tabela/listabl.asp?c=1 612\&z=p\&o=20>, 2013b. Acesso em: 01 de maio de 2015 .

MASCARENHAS, F. R.; MEDEIROS, D. C.; MEDEIROS, J. F.; DIAS, P. M. S.; SOUZA, M. S. M.; Produção e qualidade de melão gália cultivado sob diferentes níveis de salinidade. Revista Verde, Mossoró, v.5, n.5, p. 171$181,2010$.

NUNES, G. H. S.; MELO, D. R. M.; DANTAS, D. J.; ARAGÃO, F. A. S.; NUNES, E. W. L. P. Divergência genética entre linhagens de melão do grupo Inodorus. Revista Ciência Agronômica, v. 42, n. 2, p. 448-456, 2011.

NUNES, G. H. S.; PEREIRA, E. W. L.; JÚNIOR, R. S.; NETO, F. B.; OLIVEIRA, K. C.; MESQUITA, L. X. Produtividade e qualidade de frutos de melão pele-desapo em duas densidades de plantio. Horticultura Brasileira, v. 26, n. 2, p. 236-239, 2008.

PAIVA, W. O. Melhoramento genético do melão: recursos genéticos e melhoramento de plantas para o nordeste brasileiro. Fortaleza: EMBRAPA, 2002.

PEREIRA, A. V. Utilização de análise multivariada na caracterização de germoplasma de mandioca (Manihot esculenta Crantz). Piracicaba: ESALQ. 1989.

QUEIROGA, F. M.; COSTA, S. Â. D.; PEREIRA, F. H. F.; MARACUJÁ, P. B.; FILHO, A. L. S. Efeito de doses de ácido bórico na produção e qualidade de frutos de melão harper. Revista Verde, Mossoró, v.5, n.5, p. 132-139, 2010 .

QUEIROGA, R. C. F.; PUIATTI, M.; FONTES, P. C. R.; CECON, P. R. Partição de assimilados e índices fisiológicos de cultivares de melão do grupo
Cantalupensis influenciados por número e posição de frutos na planta, em ambiente protegido. Revista Ceres, v. 55, n. 6, p. 596-604, 2008.

ROCHA, R. H. C.; SILVA, E. O.; SALOMÂO, L. C. C.; VENTRELLA, M. C. Caracterização morfoanatômica do melão gália no ponto de colheita. Revista Brasileira de Fruticultura, Jaboticabal, v. 32, n. 2, p. 375-385, 2010.

SILVA, F. A. S. E.; AZEVEDO, C. A. V. Versão do programa computacional Assistat para o sistema operacional Windows. Revista Brasileira de Produtos Agroindustriais, Campina Grande, v. 4, n. 1, p. 71-78, 2002.

SILVA, J. M.; NUNES, G. H. S.; COSTA, G. G.; ARAGÃO, F. A. S.; MAIA, L. K. R. Implicações da interação genótipos $\mathrm{x}$ ambientes sobre ganhos com a seleção em meloeiro. Ciência Rural, Santa Maria, v. 41, n. 1, p. 51 $56,2011 b$.

SILVA, L. M. M.; FIGUEIRÊDO, R. M. F.; SOUSA, F. C.; SOUSA, E. P.; LIMA, A. K. V. O. Parâmetros químicos, físicos e físico-químicos de três variedades de melão. Revista Verde, Mossoró, v.6, n.5, p. 242-246, 2011 a.

VARGAS, P. F.; CASTOLDI, R.; CHARLO, H. C. O.; BRAZ, L. T. Qualidade de melão rendilhado (Cucumis melo L.) em função do sistema de cultivo. Ciência e Agrotecnologia, Lavras, v. 32, n. 1, p. 137-142, 2008a.

VARGAS, P. F.; CASTOLDI, R.; CHARLO, H. C. O.; BRAZ, L. T. Desempenho de cultivares de melão rendilhado em função do sistema de cultivo. Horticultura Brasileira, v. 26, n. 2, p. 197-201, 2008 b. 
